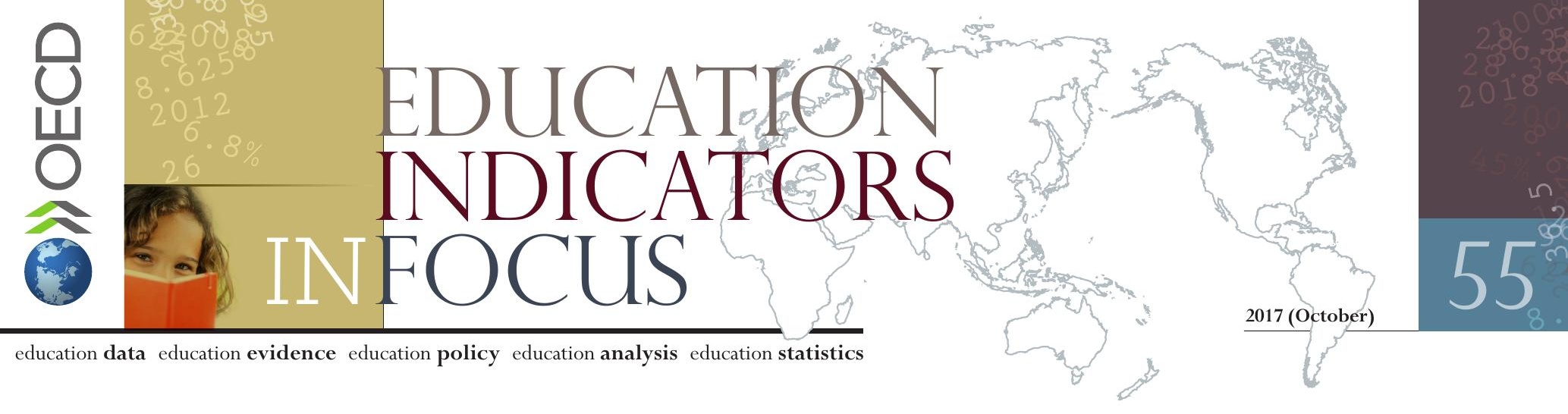

\title{
What are the gender differences and the labour market outcomes across the different fields of study?
}

- Although girls and boys perform similarly in the PISA science assessment at age 15 , girls are less likely than boys to envision a career in science and engineering, even in countries where they outperform them.

- Current gender disparities in the labour market will not be addressed by the inflow of new graduates: in all OECD and partner countries, women significantly outnumber men in education while men largely outnumber women in engineering, manufacturing and construction in both fields of study and the labour market.

- Male-dominated fields of study such as engineering, manufacturing and construction have high employment rates but also the greatest difference between the employment rates of men and women.

The choices that students make when entering tertiary education can have a major impact on the sort of work they will do after they graduate. Young men and women may base their choice of a particular field of study on predicted labour market outcomes, but other factors also come into play including availability of study places, academic interests and the expectations of their parents, peers and teachers. Their decision can often be influenced by role models and their experiences before tertiary education.

The Programme for International Student Assessment (PISA) 2015 identified gender differences in student-level factors, such as attitudes or aptitudes for specific subjects. However, these differences are not enough to fully explain the considerable gender disparities observed in the way tertiary students' choose their fields of study, suggesting that gender stereotypes may influence more strongly students at the crossroad of a career path than 15-year-olds still in school.

Labour market outcomes also differ significantly by gender even among those who graduated from the same field, particularly where men form the majority. The large gender gap in employment rates in male-dominated fields such as engineering, manufacturing and construction may discourage girls who envisage a career in this type of industry.

International Standard Classification of Education - Fields of Education and Training (ISCED-F 2013)

The International Standard Classification of Education for the Fields of Education and Training was approved at UNESCO's 37th General Conference in November 2013. The revision of ISCED-97 generated two different reference documents and classifications: the new ISCED 2011 classification which, unlike its predecessor, separated out fields of education and training, and the new ISCED-F 2013 classification which better captures the fields of study in high demand on the labour market, such as information and communication technologies (ICT).

The data collected in preparation for Education at a Glance (EAG) 2017 applied the ISCED-F 2013 classification for the first time, making new analyses by field of study possible. This EDIF presents a subset of the findings on fields of study included in EAG 2017 with a particular focus on gender disparities. It also uses data from PISA to provide insights into the career preferences of 15 year-old boys and girls.

At 15 years of age, girls are already less likely than boys to envision a career in science and engineering Despite having similar PISA science scores to boys, data from PISA 2015 show that 15 year-old girls are less likely than boys to envision themselves in a science and engineering career when they are 30. Figure 1 shows that in Finland, Greece, Latvia, Lithuania and Slovenia, girls perform statistically significantly better than boys in science. Even so, this better performance does not predict any greater interest in becoming scientists or engineers. In four of these five countries girls are significantly less likely than boys to imagine themselves in this career. These findings suggest that gender imbalances in career aspirations are not due to differences in aptitude between boys and girls. The underlying explanations for the preferences of boys and girls lie elsewhere and may be influenced by stereotypes, labour market outcomes and the division of labour in society.

Results show that some countries may have succeeded in mitigating stereotypes related to careers in science. In Iceland, Indonesia, Poland, the Russian Federation and the Slovak Republic, the gender gap in aspiration for a career in science and engineering is below 3 percentage points and not statistically significant. In these five countries, with the exception of Poland, the better gender balance in career aspiration is also accompanied by a low and non-statistically significant science performance gap between boys and girls. 
Figure 1. Gender differences in science performance and career expectation in science and engineering (2015)

15 year-old boys and girls

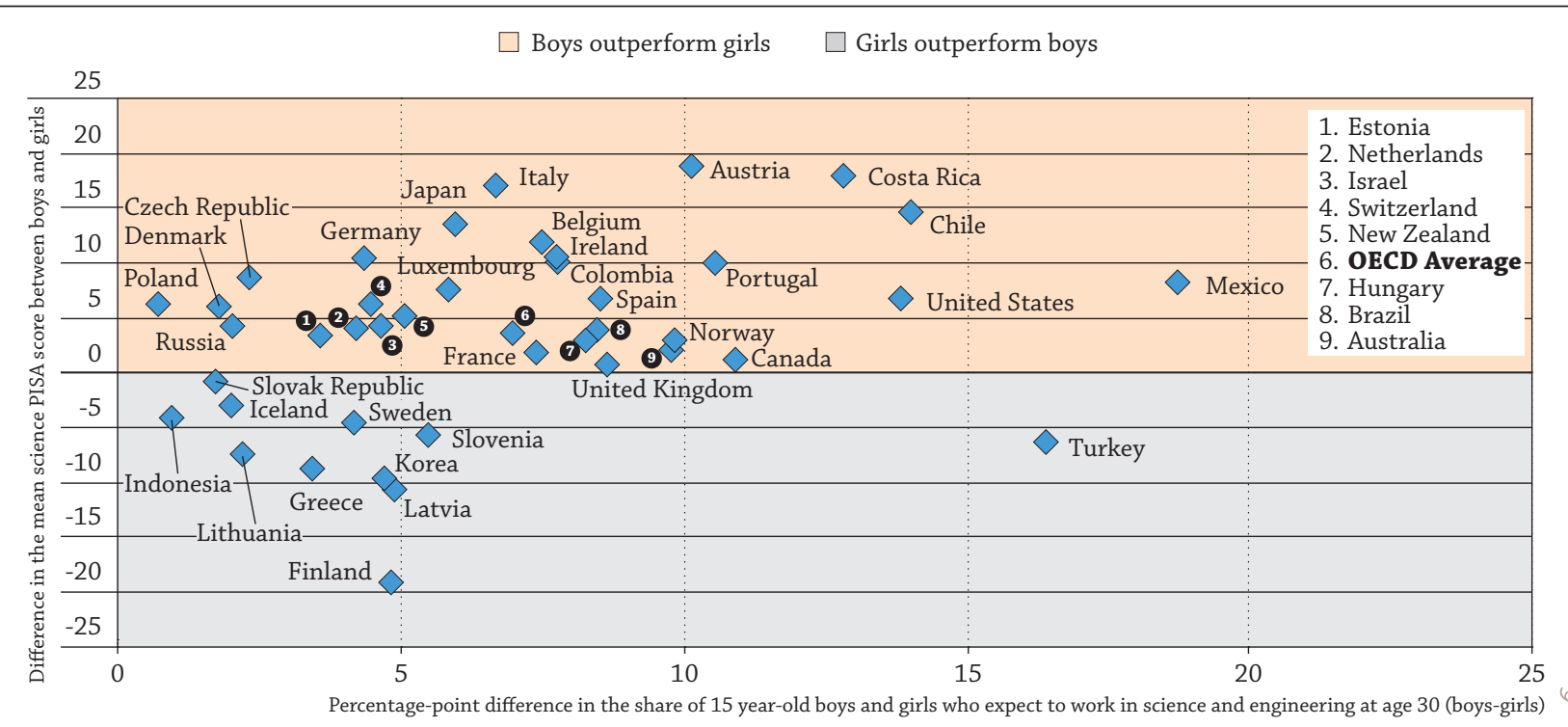

Source: OECD (2016), PISA 2015 Results (Volume I): Excellence and Equity in Education.

\section{Gender disparities in tertiary fields of study replicate the imbalances in the labour market}

When selecting their fields of study, men and women are largely influenced by the gender division in the labour market and tend to reproduce the same patterns. In some countries the gender gap in some fields of study is even larger than the gender gap in the professions these fields lead to. Figure 2 shows that on average across OECD countries the fields with the largest shares of female new entrants are education (78\%) and health and welfare (76\%). These two fields generally lead to professions that are largely dominated by women such as teaching and nursing. The high concentration of women in these fields of study means that the current gender disparities in the labour market will not be reduced by the inflow of new graduates. This appears to be particularly true in Estonia, Latvia and Slovenia where over $85 \%$ of new entrants to the field of education are women, the highest shares among OECD and partner countries. The share of women among new entrants in the field of education in these countries is higher than the share of female teachers across all levels of education. This implies that gender disparities in teaching may be set to increase even further.

In contrast with the fields of education and health and welfare, the field of engineering, manufacturing and construction and the field of information and communication technologies (ICT) are dominated by men, also reflecting the sex-typing of occupations and gender stereotypes. For example, in Japan less than 15\% of new entrants to engineering, manufacturing and construction are women, the lowest percentage across all OECD and partner countries (compared with an OECD average of 24\%). For ICT the gender disparities are even larger: only $20 \%$ of new entrants are female on average across OECD countries. As a result, there are more countries with less than $15 \%$ of female new entrants in ICT including Chile, Lithuania, Luxembourg, Poland, the Slovak Republic, Spain and Switzerland.

While the four fields of study presented in Figure 2 show strong gender disparities, others show a better gender balance. On average across OECD countries women make up between $51 \%$ and $57 \%$ of new entrants to the fields of business, administration and law; natural sciences, mathematics and statistics; agriculture, forestry, fisheries and veterinary; and services. 
Figure 2. Share of women among new entrants in tertiary education, by selected field of study (2015)

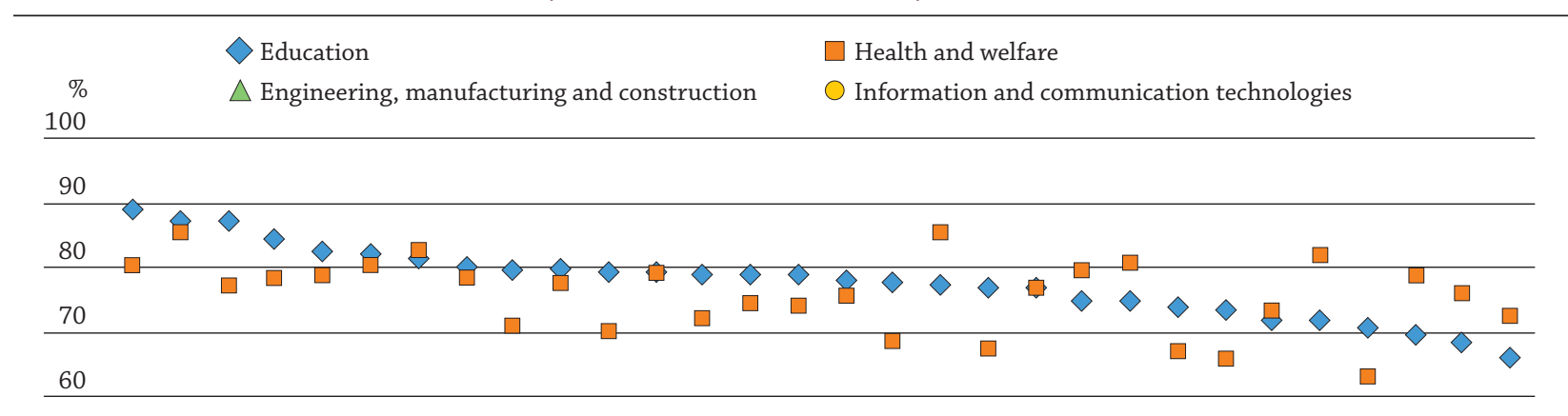

50

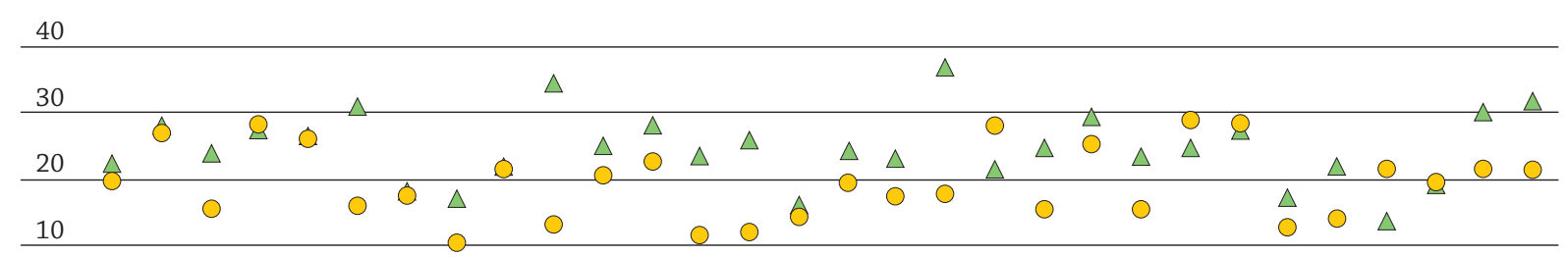

\begin{tabular}{|c|c|c|c|c|c|c|c|c|c|c|c|c|c|c|c|c|c|c|c|c|c|c|c|c|c|c|}
\hline 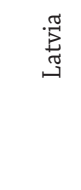 & 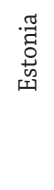 & $\begin{array}{l}. \frac{\pi}{0} \\
\stackrel{0}{\omega} \\
\text { के }\end{array}$ & $\begin{array}{l}\widetilde{\mathbb{g}} \\
\stackrel{\mathscr{\omega}}{=}\end{array}$ & $\begin{array}{l}\vec{Z} \\
\mathbb{J} \\
\mathbb{J} \\
N \\
3 \\
\text { z } \\
z\end{array}$ & 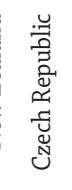 & 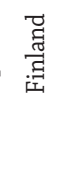 & : & 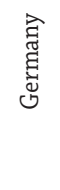 & $\begin{array}{l}\overrightarrow{0} \\
\stackrel{\pi}{0} \\
2\end{array}$ & 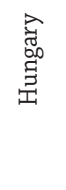 & $\begin{array}{l}\vec{J} \\
\mathbb{D}_{0} \\
\stackrel{\overrightarrow{0}}{0} \\
\stackrel{1}{1}\end{array}$ & 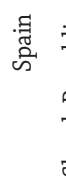 & 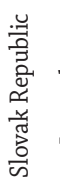 & 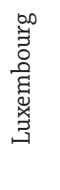 & 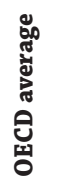 & $\begin{array}{l}\text { 㞼 } \\
\text { 蛋 }\end{array}$ & 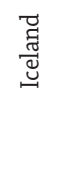 & đัّ̆ & 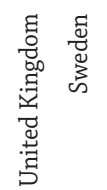 & 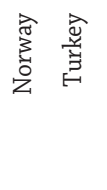 & 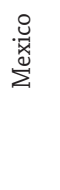 & 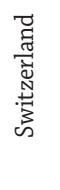 & $\begin{array}{l}\text { 恚 } \\
\text { 恚 } \\
\text { 恚 }\end{array}$ & 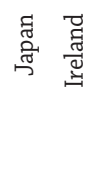 & 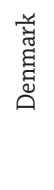 & 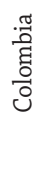 \\
\hline
\end{tabular}

Countries are ranked in descending order of the share of women among new entrants in the field of education. Source: OECD (2017), Education at a Glance Database, http://stats.oecd.org/.

\section{STEM fields have relatively high employment rates but a large gender gap}

High employment rates for graduates from certain fields of study suggest that they are in high demand in the labour market. Figure 3 shows that in 2016, employment rates were $83 \%$ for tertiary-educated 25-34 year-olds on average across OECD countries, ranging from $76 \%$ for arts and humanities to $86 \%$ for engineering, manufacturing and construction. For all fields of study with data available, men have higher employment rates than women, and the gap is particularly marked in science-related fields of study where men form the majority. While the gender gap observed in employment rates could be related to higher inactivity rates among women due to childcare responsibilities, particularly within the 25-34 age group, the larger gap observed in science-related fields compared to others reveals the higher difficulty for women in these fields to pursue their careers.

Tertiary-educated 25-34 year-olds who studied in STEM fields (science, technology, engineering and mathematics) have a high employment rate (85\%) on average across OECD countries. However, the gender gap in employment rates is 2 percentage points higher than on average across all fields of study. In all OECD countries with available data except Norway, the employment rate is higher for men than women among 25-34 year-old tertiary graduates from STEM fields. In the Czech Republic, Estonia, Hungary and the Slovak Republic, the gap is the highest among OECD countries with a difference of 23 percentage points or more. 


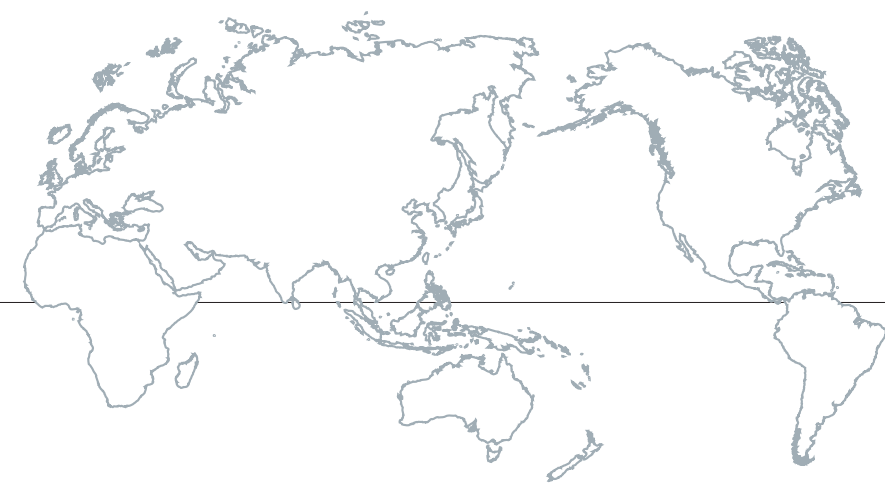

\section{Figure 3. Employment rates of tertiary-educated 25-34 year-olds, by field of study and gender (2016) \\ OECD average}

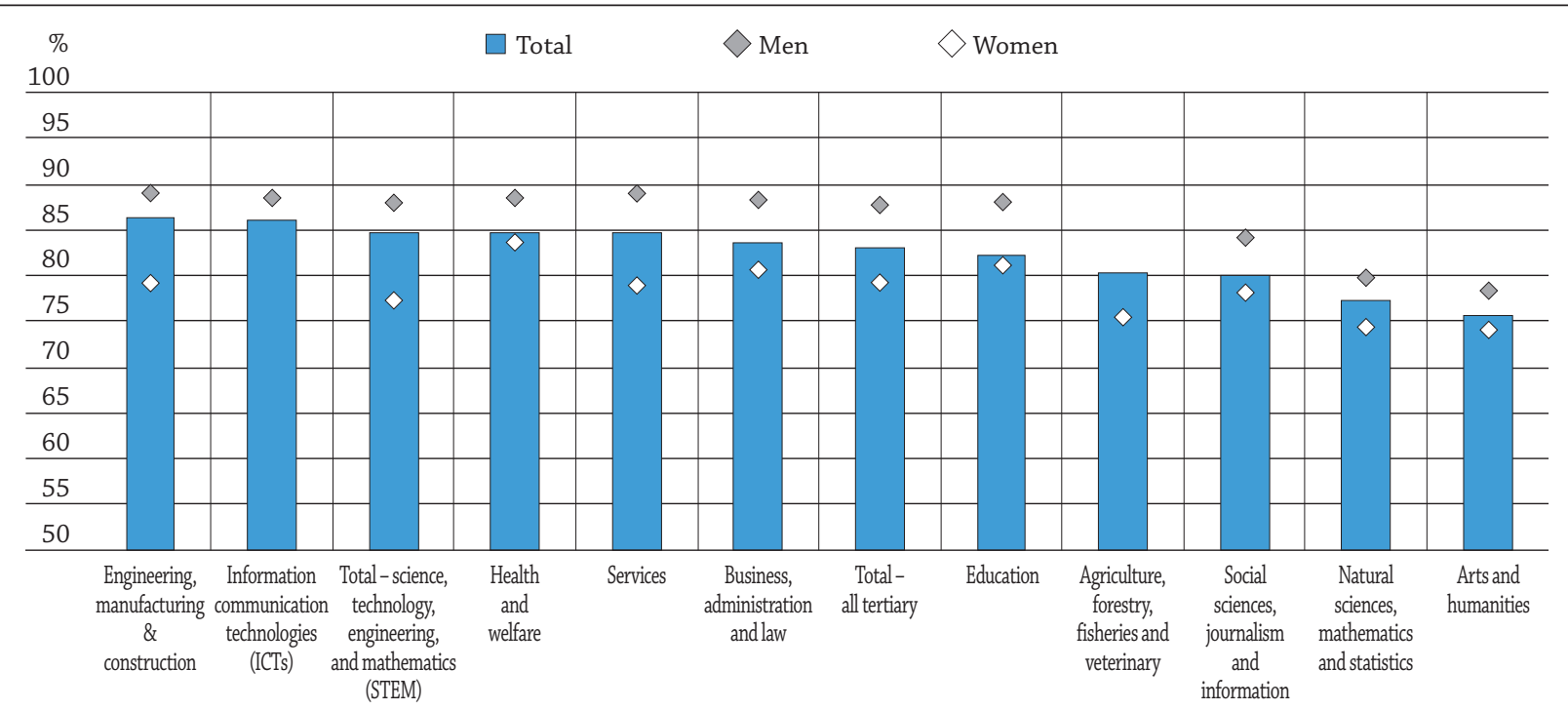

Note: The value for women who completed a degree in ICT and men who completed a degree in agriculture, forestry, fisheries and veterinary is not displayed because there are too few observations to provide reliable estimates. The employment rates include data for all OECD countries except Australia, Canada, Ireland, Israel, Japan, Korea, New Zealand, Turkey and the United Kingdom where data are missing. Science, technology, engineering and mathematics (STEM) comprise the fields of natural sciences, mathematics and statistics, information and communication technologies, and engineering, manufacturing and construction.

Fields of study are ranked in descending order of employment rate for the total.

Source: OECD (2017), Education at a Glance Database, http://stats.oecd.org/.

The bottom line: As is also seen in the labour market, some fields of study show strong gender imbalances. Most graduates from the field of education are women while most graduates from engineering, manufacturing and construction are men. Across all the fields of study with available data men have a higher employment rate than women and the gap is wider in male-dominated fields of study such as STEM fields. A better understanding of gender preferences for fields of study is needed because skills alone do not explain students' choices: despite boys and girls having similar PISA science scores, girls are being deterred from science-related fields.

\section{For more information}

- OECD (2017), Education at a Glance 2017: OECD Indicators, OECD Publishing, Paris, http://dx.doi.org/10.1787/eag-2017-en.

- OECD (2017), The Pursuit of Gender Equality: An Uphill Battle, OECD Publishing, Paris, http://dx.doi.org/10.1787/9789264281318-en.

- OECD (2016), PISA 2015 Results (Volume I): Excellence and Equity in Education, PISA, OECD Publishing, Paris, http://dx.doi. org/10.1787/9789264266490-en.

- OECD Family Database, http://www.oecd.org/els/family/database.htm, accessed on 3 October 2017.

- UIS (2014), ISCED Fields of Education and Training 2013 (ISCED-F 2013), UNESCO Institute for Statistics.

- UIS (2012), International Standard Classification of Education: ISCED 2011, UNESCO Institute for Statistics, Montreal.

\section{Contact}

Simon Normandeau (simon.normandeau@oecd.org) and Junyeong Park (junyeong.park@oecd.org).

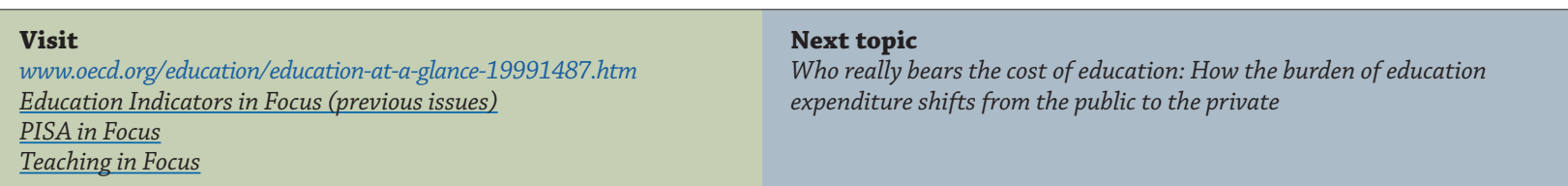

Photo credit: @ Ghislain \& Marie David de Lossy/Cultura/Getty Images

This work is published under the responsibility of the Secretary-General of the OECD. The opinions expressed and arguments employed herein do not necessarily reflect the official views of OECD member countries.

Views OF OECD member countries. This document, as well as any data and any map included herein, are without prejudice to the status of or sovereignty over any territory, to the delimitation of international frontiers and boundaries and to the name of any territory, city or area.

The statistical data for Israel are supplied by and are under the responsibility of the relevant Israeli authorities. The use of such data by the OECD is without prejudice to the status of the Golan Heights, East Jerusalem and Israeli settlements in the West Bank under the terms of international law. 